\title{
One leg standing time predicts fracture risk in older women independent of clinical risk factors and BMD
}

\author{
B.A.M. Larsson ${ }^{1} \cdot$ L. Johansson ${ }^{1,2} \cdot$ D. Mellström ${ }^{1} \cdot$ H. Johansson ${ }^{1,3} \cdot$ K.F. Axelsson ${ }^{1,4} \cdot$ N. Harvey $^{5,6} \cdot$ L. Vandenput ${ }^{1,3} \cdot$ \\ E. McCloskey ${ }^{7,8}$ - E. Liu $^{3}$ - D. Sundh ${ }^{1}$ - J.A. Kanis ${ }^{3,7} \cdot$ M. Lorentzon ${ }^{1,3,9}$
}

Received: 20 April 2021 / Accepted: 15 June 2021 / Published online: 8 September 2021

(C) The Author(s) 2021

\begin{abstract}
Summary In women of ages 75-80 years, a low one leg standing time (OLST) was associated with an increased risk of incident fractures, independently of bone mineral density and clinical risk factors. OLST contributed substantially to fracture probability, indicating that the test should be considered when evaluating fracture risk in older women.

Introduction Physical function and risk of falls are important risk factors for fracture. A few previous studies have suggested that a one leg standing time (OLST) less than $10 \mathrm{~s}$ predicts fracture risk, but the impact of OLST, in addition to known clinical risk factors, for fracture probability is unknown. The aim of this study was to determine the independent contribution of OLST to fracture probability in older women.

Methods The Sahlgrenska University Hospital Prospective Evaluation of Risk of Bone Fractures (SUPERB) is a prospective population-based study of 3028 women 75-80 years old, recruited from the greater Gothenburg area in Sweden. At baseline, information on risk factors was collected using questionnaires, bone mineral density was measured with dual-energy X-ray absorptiometry (DXA), and OLST was performed.

Results During a median follow-up of 3.6 years (IQR 1.5 years), X-ray-verified incident fractures were identified using health records. OLST was available in 2405 women. OLST less than $10 \mathrm{~s}$ was associated with an increased risk for incident hip fracture (Hazard Ratio (HR) 3.02, 95\% Confidence Interval (CI) [1.49-6.10]), major osteoporotic fracture (HR 95\% CI 1.76 [1.34-1.46]), and nonvertebral fracture (HR 95\% CI 1.61 [1.26-2.05]) in Cox regression analyses adjusted for age, height, and weight. Depending on BMD, the 4-year fracture probability increased by a factor of 1.3 to 1.5 in a 75 -year-old woman with a low OLST $(<10 \mathrm{~s})$.

Conclusion A low OLST has a substantial impact on fracture probability and should be considered when evaluating fracture risk in older women.
\end{abstract}

Keywords Clinical risk factors and bone mineral density $\cdot$ Epidemiology $\cdot$ Fracture risk · Osteoporosis · The one leg standing test

M. Lorentzon

mattias.lorentzon@acu.edu.au; mattias.lorentzon@medic.gu.se

1 Sahlgrenska Osteoporosis Centre, Department of Internal Medicine and Clinical Nutrition, Institute of Medicine, University of Gothenburg, Gothenburg, Sweden

2 Region Västra Götaland, Department of Orthopaedics, Sahlgrenska University Hospital, Mölndal, Sweden

3 Mary MacKillop Institute for Health Research, Australian Catholic University, Melbourne, VIC, Australia

4 Region Västra Götaland, Närhälsan Norrmalm Health Centre, Skövde, Sweden
5 MRC Lifecourse Epidemiology Unit, University of Southampton, Southampton, UK

6 NIHR Southampton Biomedical Research Centre, University of Southampton and University Hospital Southampton NHS Foundation Trust, Tremona Road, Southampton, UK

7 Centre for Metabolic Bone Diseases, University of Sheffield Medical School, Sheffield, UK

$8 \quad$ MRC and Arthritis Research UK Centre for Integrated Research in Musculoskeletal Ageing, Mellanby Centre for Bone Research, University of Sheffield, Sheffield, UK

9 Region Västra Götaland, Department of Geriatric Medicine, Sahlgrenska University Hospital, Mölndal, Sweden 


\section{Introduction}

Physical function and balance decline with age and affect the risk of injurious falls [1-3]. Fractures in older women have serious implications both for society and on a personal level, as reflected by patients suffering from pain as well as a worsened quality of life following the fracture $[4,5]$. In addition, impaired physical function, reduced opportunity to participate in social activities, isolation, decreased independence in daily life, and a deteriorating quality of life in general are common consequences of fracture [6-8]. Fractures are also associated with an increased risk of mortality, especially hip fractures $[9,10]$. A further negative consequence of hip fractures, in particular, is that special accommodation often is required for the remaining lifetime. Living in a residential aged care facility has great impact on the affected person's autonomy [11-13] as well as on the society [14-16].

The majority of all fractures affect women older than 65 years [17]. The increasing fracture incidence linked to rising age has multifactorial causes such as fall risk, reduced physical performance, sarcopenia, bone fragility, and general frailty [18-20]. Immobility and previous falls per se are risk factors for future fractures [21]. The risk of hip fracture increases nearly 3 times with every standard deviation decrease in bone mineral density (BMD) in the femoral neck [22]. However, BMD alone as a fracture predictor has low sensitivity. Therefore, fracture risk calculators which take into account both BMD and clinical risk factors have been developed, of which FRAX ${ }^{\circledR}$ is the most widespread and most thoroughly validated [23].

The one leg standing time (OLST) test measures balance and physical performance, is a strong predictor of falls [24-27], has been used to identify frail older individuals, and has in various studies been documented with good test-retest reproducibility as well as acceptable reliability [28]. A low OLST $(<10 \mathrm{~s})$ has been associated with increased risk of fracture in previous studies, but these studies have either been small, with few hip fracture outcomes [29, 30] or lacked adjustment for other commonly used risk factors, such as those included in FRAX [29]. Furthermore, the minimal time associated with a risk increase, varies among different studies, implying that the best cut-off time for defining OLST in relation to risk for fractures has not yet been defined [31].

The aim of the present study was to study the relationship between OLST and risk of nonvertebral fracture, major osteoporotic fracture, and hip fracture, and to investigate how OLST contributes to fracture probabilities in addition to BMD and all clinical risk factors used in FRAX.

\section{Materials and methods}

\section{Subjects}

The Sahlgrenska University Hospital Prospective Evaluation of Risk of Bone Fractures (SUPERB) is a prospective population-based study, carried out in the greater Gothenburg area. Women were chosen randomly from the Swedish national population register and asked to participate through invitation letters. In total, 6832 women were initially contacted, of which 436 (6.4\%) were excluded for reasons including bilateral hip replacement, inability to communicate in Swedish, or not being able to walk with or without a walking aid. Of all women contacted who met the inclusion criteria, $3368(52.6 \%)$ declined to participate, resulting in an inclusion rate of $47.4 \%$ [32]. Thus, the final SUPERB study cohort comprised 3028 women, $75-80$ years old. All subjects signed an informed consent, prior to participation and the study has been approved by the Swedish Ethical Review Authority. The criteria for invitation to the study center, Department of Geriatrics, Sahlgrenska University Hospital Mölndal, Sweden, were as follows: (1) acceptance of the invitation sent by letter and giving a positive response of the follow-up telephone call, (2) availability to attend a clinic visit, (3) being ambulatory, (4) being able to understand Swedish, (5) being a woman between the age of 75 and 80 .

\section{Anthropometrics and OLST}

A wall-mounted calibrated stadiometer was used to measure body height. Balance was measured by the clinical balance test OLST [33]. The OLST was performed with the tested participant not wearing shoes, standing on one leg with the other leg bending backwards at the knee, with arms crossed over the chest, and with eyes open. After a practice session, the test was performed twice for each leg. The test was stopped if the elevated leg touched the floor, if the position of the arms was changed, or if the foot standing on changed position. The average of the best result for either leg was used as the exposure. In total, 623 women declined to perform the test, resulting in an available OLST in 2405 women.

\section{Questionnaires}

The questionnaires had two parts, comprising a selfcompleted form and a form completed in discussion with the research nurse. The questionnaire covered eight different domains, including medical and fracture history, use of medication, current smoking, occurrence of falls in the last 12 months, alcohol consumption, and parental hip fracture. Information regarding physical activity and self-reported quality of life were collected using the 12-Item Short-Form Health Survey (SF-12), yielding a physical (PCS) and mental 
summary (MSC) score [34]. Physical activity habits were investigated with the Physical Activity Scale for the Elderly (PASE) [35] survey.

\section{Dual-energy X-ray absorptiometry measures}

Dual-energy X-ray absorptiometry (DXA) was used for assessment of bone mineral density (BMD) and body composition. The locations of BMD measurements were the lumbar spine (L1-L4), the femoral neck, and the total hip. A total body scan was used in order to estimate the amount of fat and lean body mass. The coefficients of variation $(\mathrm{CVs})$, at our facility, were $0.7 \%$ for lumbar spine BMD, $0.8 \%$ for total hip BMD, and $1.3 \%$ for femoral neck BMD, for women aged 75-80. The DXA machine used for assessment was a Hologic Discovery A device (Hologic, Waltham, MA, USA).

\section{Incident fracture assessment}

A regional digital X-ray archive including all the 49 municipalities in the Västra Götaland region surrounding Gothenburg was used to retrieve the images and/or X-ray reports. All fractures were recorded and were subsequently categorized as major osteoporotic fracture (MOF), nonvertebral fracture, and hip fracture. MOF comprised fractures of the spine, hip, forearm, and proximal humerus. Skull, face, hand, and foot fractures were excluded from nonvertebral fractures. All the radiology reports were reviewed by research nurses and a physician. This assessment was carried out from the baseline exam (March 2013 to April 2016) until May 24, 2018. Identified radiographs without an available radiology report or a report without a specified fracture diagnosis were reviewed by an experienced orthopedic surgeon.

\section{Statistical analyses}

All statistical analyses were conducted via SPSS Statistics version 24 (IBM Corporation, Armonk, NY, USA) or STATA 16.0 (StataCorp, College Station, TX, USA). For continuous variables, independent samples t-tests were used to examine differences between groups. $\chi^{2}$ and Fisher's exact tests were used for dichotomous variables. The association between OLST as a continuous variable and the risk of fracture was examined using an extension of the Poisson regression model $[36,37]$ in the whole cohort. The observation period of each participant was divided in intervals of 1 month. The first fracture per person was counted for each relevant outcome. Covariates included current age and time since start of follow-up. A spline Poisson regression model was fitted using cohort-specific knots at the $10^{\text {th }}, 50^{\text {th }}$, and $80^{\text {th }}$ percentiles of OLST, corresponding to OLST $2.94 \mathrm{~s}, 11.48 \mathrm{~s}$, and $24.58 \mathrm{~s}$, in order to study the association between OLST and fracture risk in more detail. The splines were second-order functions between the breakpoints and linear functions at the tails resulting in a smooth curve. A p-value less than 0.05 was considered significant. Since no apparent threshold in the relationship was seen, particularly for hip fracture, the previously proposed 10 -s $[30,38,39]$ threshold was applied to identify a high-risk group. Cox proportional hazard models were also used to study associations between OLST (OLST $<10 \mathrm{~s}$ or $\geq 10 \mathrm{~s})$ mortality and incident fractures. The models were adjusted for age, height, and weight as well as additional covariates, as specified in Table 2. Hazard ratios (HR) and 95\% confidence intervals obtained from Cox models are presented. To assess death as a competing risk for osteoporotic fractures, Fine and Gray's hazard function was used [40]. Hazard functions for fracture and death were used to calculate 4-year and 10-year probabilities.

\section{Results}

\section{Baseline characteristics, OLST, and association with fracture}

The mean age of included women was $77.7 \pm 1.6$ years at baseline (mean $\pm \mathrm{SD}$ ) and the follow-up time was 3.6 (1.5) years (median, interquartile range (IQR)). During follow-up, 82 women died and 238 major osteoporotic fractures, 44 hip fractures, and 228 nonvertebral fractures were observed in the investigated cohort. Women who declined to take the OLST had a greater BMI, were less physically active, and had higher prevalence of previous falls, fractures, and of most comorbidities than women who performed the OLST (Supplemental Table 1a).

The relationship between OLST, incident major osteoporotic fractures, and hip fracture showed a steady increase in fracture risk with declining OLST (Fig. 1a, b). The included participants were divided into two groups, OLST $<10 \mathrm{~s}(\mathrm{n}=1094)$ and OLST $\geq 10 \mathrm{~s}(\mathrm{n}=1311)$. Characteristics of women with OLST $<10 \mathrm{~s}$ and women with OLST $\geq 10 \mathrm{~s}$ at baseline are presented in Table 1. Women with OLST $<10 \mathrm{~s}$ were slightly older, weighed more, and had higher body mass index (BMI) than women with higher OLST (Table 1). In addition, an OLST $<10 \mathrm{~s}$ was also associated with slightly higher lumbar spine BMD, while no differences in hip BMD or FRAX scores (with the exception of a slightly higher FRAX MOF score for those with low OLST) were observed between the low and high OLST groups.

Women with low OLST had higher prevalence of fall accidents during the last year, but not of prevalent fractures than those with higher OLST (Table 1). Furthermore, low OLST was associated with higher frequencies of smoking and excessive alcohol consumption as well as with higher 
Table 1 Characteristics of older women according to the one leg standing test (OLST) time

\begin{tabular}{|c|c|c|c|}
\hline & $\begin{array}{l}\text { OLST }<10 \mathrm{~s} \\
(\mathrm{n}=1094)\end{array}$ & $\begin{array}{l}\text { OLST } \geq 10 \mathrm{~s} \\
(\mathrm{n}=1311)\end{array}$ & p-value ${ }^{a}$ \\
\hline Age (years) & $78.1 \pm 1.6$ & $77.4 \pm 1.6$ & $<0.001$ \\
\hline Height $(\mathrm{cm})$ & $161.9 \pm 5.9$ & $162.0 \pm 5.6$ & 0.670 \\
\hline Weight (kg) & $69.6 \pm 11.8$ & $65.4 \pm 10.1$ & $<0.001$ \\
\hline Body mass index $\left(\mathrm{kg} / \mathrm{m}^{2}\right)$ & $26.5 \pm 4.3$ & $24.9 \pm 3.6$ & $<0.001$ \\
\hline Femoral neck BMD $\left(\mathrm{g} / \mathrm{cm}^{2}\right)(\mathrm{n})$ & $0.66 \pm 0.10^{\mathrm{s}}$ & $0.66 \pm 0.10^{1}$ & 0.576 \\
\hline Total hip BMD $\left(\mathrm{g} / \mathrm{cm}^{2}\right)(\mathrm{n})$ & $0.80 \pm 0.12^{\mathrm{s}}$ & $0.80 \pm 0.11^{1}$ & 0.304 \\
\hline Lumbar spine BMD (g/cm²) (n) & $0.94 \pm 0.18$ & $0.93 \pm 0.16^{\mathrm{b}}$ & 0.041 \\
\hline FRAX MOF w/o BMD (\%) & $31.0 \pm 12.1^{\mathrm{u}}$ & $31.2 \pm 12.2^{\mathrm{v}}$ & 0.620 \\
\hline FRAX hip fracture w/o BMD (\%) & $18.1 \pm 12.4^{\mathrm{u}}$ & $18.7 \pm 12.5^{\mathrm{v}}$ & 0.284 \\
\hline FRAX MOF with BMD (\%) & $23.4 \pm 11.8^{\mathrm{w}}$ & $22.4 \pm 11.5^{\mathrm{x}}$ & 0.042 \\
\hline FRAX hip fracture with BMD (\%) & $11.3 \pm 11.1^{\mathrm{w}}$ & $10.6 \pm 10.9^{\mathrm{x}}$ & 0.168 \\
\hline Physical Activity Scale for the Elderly (PASE) & $101.3 \pm 48.5^{\mathrm{s}}$ & $118.6 \pm 50.6^{\mathrm{g}}$ & $<0.001$ \\
\hline Physical component score (SF-12) & $42.6 \pm 10.4^{\mathrm{s}}$ & $48.6 \pm 9.3^{\circ}$ & $<0.001$ \\
\hline Mental component score (SF-12) & $53.9 \pm 9.2^{\mathrm{s}}$ & $54.3 \pm 8.6^{\circ}$ & $<0.001$ \\
\hline Fall accident within the last year, $\%(\mathrm{n})^{\mathrm{a}}$ & $28.6(313)$ & $23.3(306)$ & 0.003 \\
\hline Self-reported prior fracture, $\%(n)^{a, f}$ & $36.6(399)^{\mathrm{n}}$ & $35.3(462)^{\mathrm{b}}$ & 0.496 \\
\hline Parental history of hip fracture, $\%(n)^{\mathrm{f}}$ & $18.4(199)^{\mathrm{r}}$ & $17.3(225)^{\mathrm{q}}$ & 0.501 \\
\hline Current smoking, $\%(\mathrm{n})^{\mathrm{a}}$ & $5.8(63)^{\mathrm{d}}$ & $3.9(51)^{\mathrm{b}}$ & 0.032 \\
\hline Excessive alcohol consumption, $\%(n)^{\mathrm{g}}$ & $0.8(9)^{\mathrm{d}}$ & $0.2(3)$ & 0.039 \\
\hline \multicolumn{4}{|l|}{ Medications $^{\mathrm{a}}$} \\
\hline Glucocorticoid use, $\%(n)^{\mathrm{h}}$ & $3.0(33)^{\mathrm{t}}$ & $3.4(45)$ & 0.575 \\
\hline Osteoporosis medication, \% (n) ${ }^{\mathrm{i}}$ & $17.2(225)^{\mathrm{b}}$ & $17.3(189)$ & 0.240 \\
\hline \multicolumn{4}{|l|}{ Medical history $^{\mathrm{a}}$} \\
\hline Rheumatoid arthritis, \% (n) & $2.8(31)^{\mathrm{m}}$ & $2.8(36)^{1}$ & 0.898 \\
\hline Hyperthyroidism, \% (n) & $4.9(54)^{\mathrm{m}}$ & $4.5(59)^{\mathrm{o}}$ & 0.614 \\
\hline Hypothyroidism, \% (n) & $14.4(157)^{\mathrm{n}}$ & $13.2(173)^{\mathrm{p}}$ & 0.409 \\
\hline Osteoporosis, \% (n) ${ }^{\mathrm{j}}$ & $19.6(214)^{\mathrm{d}}$ & $19.1(251)$ & 0.789 \\
\hline Hypertension, \% (n) & $55.7(609)^{d}$ & $46.8(613)$ & $<0.001$ \\
\hline Stroke, $\%(\mathrm{n})$ & $6.4(70)^{\mathrm{d}}$ & $4.9(64)$ & 0.105 \\
\hline Myocardial infarction, \% (n) & $4.8(52)^{\mathrm{d}}$ & $3.1(41)$ & 0.039 \\
\hline Angina, \% (n) & $4.4(48)^{\mathrm{m}}$ & $4.4(57)^{\mathrm{b}}$ & 0.958 \\
\hline Chronic heart failure, $\%(n)$ & $9.2(101)^{\mathrm{d}}$ & $5.9(78)$ & 0.002 \\
\hline Parkinson's disease, \% (n) & $0.5(6)^{\mathrm{d}}$ & $0.3(4)$ & 0.355 \\
\hline Type 2 diabetes, \% (n) & $10.5(114)^{\mathrm{s}}$ & $5.7(75)^{1}$ & $<0.001$ \\
\hline Chronic liver disease, $\%(n)$ & $0.5(5)^{\mathrm{n}}$ & $0.3(4)^{\mathrm{b}}$ & $0.388^{\mathrm{e}}$ \\
\hline Celiac disease, $\%(\mathrm{n})$ & $1.2(13)^{\mathrm{n}}$ & $1.5(20)^{\mathrm{b}}$ & 0.484 \\
\hline Chronic bronchitis, asthma, emphysema, \% (n) & $10.4(114)^{\mathrm{d}}$ & $6.9(91)$ & 0.002 \\
\hline Cancer, $\%(\mathrm{n})$ & $19.6(214)^{\mathrm{m}}$ & $20.8(273)$ & 0.456 \\
\hline Glaucoma, \% (n) & $7.9(86)^{\mathrm{d}}$ & $7.4(97)$ & 0.666 \\
\hline
\end{tabular}

Values are presented as mean \pm standard deviation for continuous variables and as percentage and number for categorical variables. Significance was defined by a p-value $<0.05$ and significant values are presented in bold. ${ }^{a}$ Categorical variables were compared with the $\chi^{2}$ test. ${ }^{\mathrm{b}}(1310) .{ }^{\mathrm{c}}(1030)$. ${ }^{\mathrm{d}}$ (1093). ${ }^{\mathrm{e}}$ Fisher's exact test. ${ }^{\mathrm{f}}$ After 50 years of age. Fractures of the skull and face are excluded. ${ }^{\mathrm{g}} 21$ or more units per week. ${ }^{\mathrm{h}}$ Daily oral treatment with at least $5 \mathrm{mg}$ for 3 months or more ever during lifetime. ${ }^{\mathrm{i}}$ Current treatment with bisphosphonates, teriparatide, or denosumab. ${ }^{\mathrm{j}}$ Self-reported. $S F-12,12-$ Item Short-Form Health Survey. ${ }^{\mathrm{k}}(1259) .{ }^{1}(1308) .{ }^{\mathrm{m}}(1092) .{ }^{\mathrm{n}}(1090) .{ }^{\mathrm{o}}(1309) .{ }^{\mathrm{p}}(1307) .{ }^{\mathrm{q}}(1297) .{ }^{\mathrm{r}}(1081) .{ }^{\mathrm{s}}(1088) .{ }^{\mathrm{t}}(1091) .{ }^{\mathrm{u}}(1075){ }^{\mathrm{v}}(1293) .{ }^{\mathrm{w}}(1069)$ $\mathrm{x}(1290)$

prevalence of several diseases or conditions, including chronic heart failure, type 2 diabetes, myocardial infarction, chronic bronchitis, asthma, or emphysema, reflecting increased frailty (Table 1). 

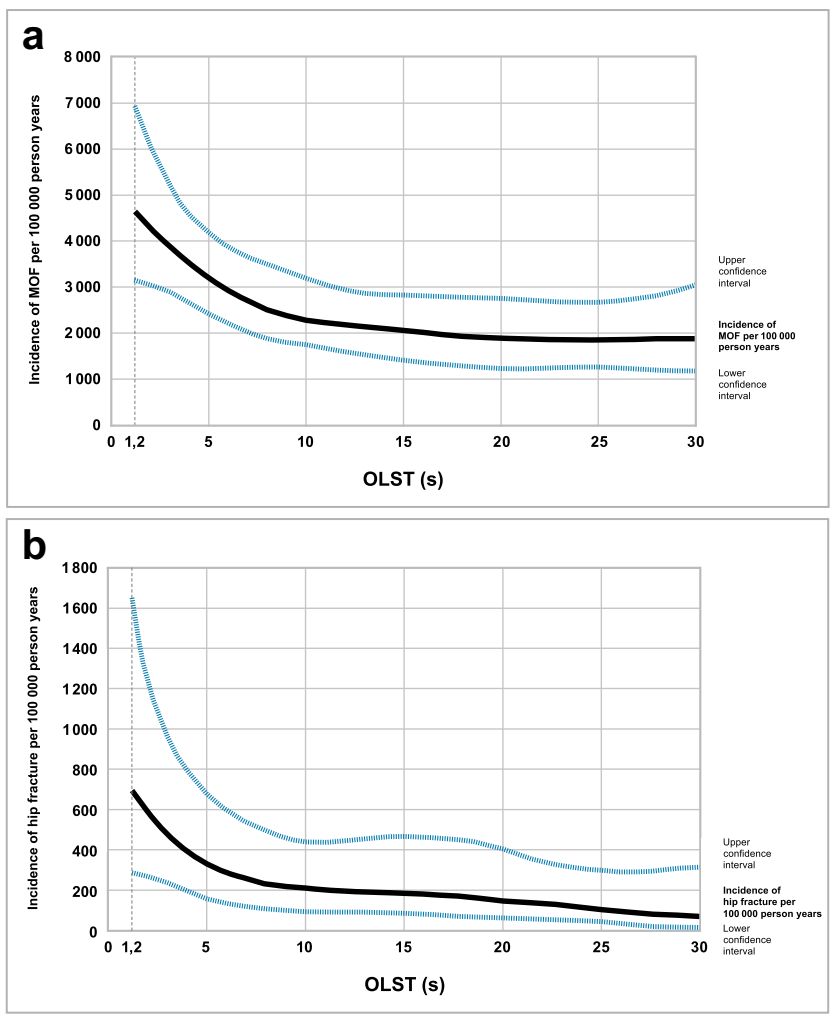

Fig. 1 a The relationship between one leg standing test (OLST) time and incidence of major osteoporotic fracture (MOF). Incidence and 95\% confidence intervals of MOF according to OLST (s) are described per 100,000 person-years. b The relationship between one leg standing test (OLST) time and incidence of hip fracture. Incidence and 95\% confidence intervals of hip fracture according to OLST (s) are described per 100,000 person-years

\section{Low OLST and associations with incident fractures and death}

The incidence of nonvertebral fracture, major osteoporotic fracture, and hip fracture was higher in women with OLST $<10 \mathrm{~s}$ than in women with OLST $\geq 10 \mathrm{~s}$. With adjustment for age, height, and weight, a Cox proportional hazard model revealed that OLST $<10 \mathrm{~s}$ (vs. $\geq 10 \mathrm{~s}$ ) was associated with $61 \%$ increased risk of nonvertebral fracture (hazard ratio (HR) and 95\% confidence interval (CI) 1.61 [1.27-2.06]), $76 \%$ increased risk of major osteoporotic fractures (HR, 95\% CI 1.76 [1.34-2.30]), and 3 times increased risk of hip fracture (HR, 95\% CI 3.02 [1.50-6.10]). OLST was associated with all fracture outcomes also after adjustments for the FRAX clinical risk factors (previous fracture, family history of hip fracture, current smoking, oral glucocorticoid use, rheumatoid arthritis, excessive alcohol intake), osteoporosis medication, and history of falls both in models with and without femoral neck BMD included (Table 2). In total, $4.8 \%$ of women with a low OLST died during follow-up, compared to $2.2 \%$ in women with longer OLST, corresponding to an $82 \%$ increased risk of death (Table 2).

\section{The impact of OLST $<10 \mathrm{~s}$ on fracture probabilities}

The 4-year probabilities of major osteoporotic fracture for women at age 75 or 80 years old, without previous fracture, BMI of $26 \mathrm{~kg} / \mathrm{m}^{2}$, and no additional clinical risk factors, were also calculated according to femoral neck BMD T-score, with or without consideration to OLST $(<10 \mathrm{~s}$ or $\geq 10 \mathrm{~s})$ in the analysis. For a 75 -year-old woman with BMD T-score -2 , OLST $<10 \mathrm{~s}$ was associated with a higher 4-year probability $(12.5 \%$ vs. $8.0 \%)$. The corresponding 4 -year probability for an 80-year-old woman with a T-score of -2 was $12.0 \%$ and $7.7 \%$ for OLST ( $<10 \mathrm{~s}$ or $\geq 10 \mathrm{~s}$ ), respectively (Fig. 2a, b). The ratios between the calculated 4-year probability without considering OLST and with OLST $<10$ s for women 75 and 80 years old, without previous fracture, BMI of $26 \mathrm{~kg} / \mathrm{m}^{2}$ and no other clinical risk factors, according to femoral neck BMD T-score are presented in Fig. 3. The relative importance on fracture probability of having OLST $<10 \mathrm{~s}$ was slightly greater at higher BMD in both 75- and 80-year-old women. Study subject follow-up time was then extrapolated up to 10 years to allow for calculations of 10 -year fracture probability. The 10year probabilities of major osteoporotic fracture for women 75 and 80 years old were calculated, setting BMI to $26 \mathrm{~kg} / \mathrm{m}^{2}$, and all clinical risk factors set to no, according to femoral neck BMD T-score, with or without consideration to OLST $(<10 \mathrm{~s}$ or $\geq 10 \mathrm{~s}$ ) in the analysis. For a 75 -year-old woman with BMD T-score -2 , a low OLST $<10 \mathrm{~s}$ increased the 10-year probability substantially, from 21.1 to $30.6 \%$. The equivalent 10 year probability for an 80-year-old woman with a T-score of -2 was $19.7 \%$ and $28.0 \%$, for OLST $\geq 10 \mathrm{~s}$ or $<10 \mathrm{~s}$, respectively (Fig. 2c, d). The impact of OLST on 10-year fracture probabilities according to age and BMD is presented in Appendix Table 1b, c.

\section{The impact of competing risk of death according to Fine and Gray}

The association between OLST $<10 \mathrm{~s}$ and risk for major osteoporotic fracture (subhazard ratio (SHR) and 95\% CI: 1.56 (1.18-2.06)), hip fracture (SHR 2.37 (1.13-4.96)), and nonvertebral fracture (SHR $1.41(1.06-1.86))$ did not change substantially when a competing risk survival regression model, adjusted for age, height, and weight, was applied.

\section{Discussion}

In the current study, we demonstrate that OLST is an independent predictor of nonvertebral fracture, major osteoporotic fracture, and hip fracture regardless of FRAX clinical risk 
Table 2 Associations between OLST $<10 \mathrm{~s}$ and fracture risk in older women

\begin{tabular}{|c|c|c|}
\hline & $\begin{array}{l}\text { OLST }<10 \mathrm{~s} \\
(\mathrm{n}=1094)\end{array}$ & $\begin{array}{l}\text { OLST } \geq 10 s \\
(n=1311)\end{array}$ \\
\hline \multicolumn{3}{|l|}{ Nonvertebral fracture } \\
\hline No. $(\%)$ & $131(12.0)$ & $97(7.4)$ \\
\hline Per 1000 person-years & 34.3 & 22.3 \\
\hline Time at risk, median (IQR), years & $3.7(1.6)$ & $3.2(1.7)$ \\
\hline \multicolumn{3}{|l|}{$\mathrm{HR}(95 \% \mathrm{CI})$} \\
\hline Adjusted for age, height, weight (model 1) & $1.61[1.27-2.06]$ & 1 [Reference] \\
\hline + FRAX clinical risk factors (model 2) & $1.54[1.20-1.97]$ & 1 [Reference] \\
\hline + FN BMD (model 3) & $1.46[1.14-1.87]$ & 1 [Reference] \\
\hline \multicolumn{3}{|l|}{ Major osteoporotic fracture } \\
\hline No. $(\%)$ & $144(13.2)$ & $94(7.2)$ \\
\hline Per 1000 person-years & 38.0 & 21.6 \\
\hline Time at risk, median (IQR), years & $3.7(1.6)$ & $3.2(1.6)$ \\
\hline \multicolumn{3}{|l|}{$\operatorname{HR}(95 \% \mathrm{CI})$} \\
\hline Adjusted for age, height, weight (model 1) & $1.76[1.34-2.30]$ & 1 [Reference] \\
\hline + FRAX clinical risk factors (model 2) & $1.67[1.27-2.20]$ & 1 [Reference] \\
\hline + FN BMD (model 3) & $1.58[1.20-2.08]$ & 1 [Reference] \\
\hline \multicolumn{3}{|l|}{ Hip fracture } \\
\hline No. $(\%)$ & $33(3.0)$ & $11(0.8)$ \\
\hline Per 1000 person-years & 8.2 & 2.5 \\
\hline Time at risk, median (IQR), years & $3.8(1.5)$ & $3.3(1.6)$ \\
\hline \multicolumn{3}{|l|}{$\mathrm{HR}(95 \% \mathrm{CI})$} \\
\hline Adjusted for age, height, weight (model 1) & $3.02[1.50-6.10]$ & 1 [Reference] \\
\hline + FRAX clinical risk factors (model 2) & $2.90[1.43-5.89]$ & 1 [Reference] \\
\hline + FN BMD (model 3) & $2.39[1.17-4.86]$ & 1 [Reference] \\
\hline \multicolumn{3}{|l|}{ Death } \\
\hline No. $(\%)$ & $53(4.8)$ & $29(2.2)$ \\
\hline Per 1000 person-years & 13.0 & 6.4 \\
\hline Time at risk, median (IQR), years & $3.8(1.4)$ & $3.3(1.6)$ \\
\hline \multicolumn{3}{|l|}{$\mathrm{HR}(95 \% \mathrm{CI})$} \\
\hline Adjusted for age, height, weight (model 1) & $1.82[1.14-2.92]$ & 1 [Reference] \\
\hline
\end{tabular}

Associations were studied using Cox proportional hazard models. Hazard ratios (HR) and 95\% confidence intervals (CI) are presented. Model 1: adjusted for age, height, and weight. Model 2: adjusted for age, height, weight, and the FRAX clinical risk factors as previous fracture, family history of hip fracture, current smoking, oral glucocorticoid use, osteoporosis medication, rheumatoid arthritis, excessive alcohol intake, and history of falls. Model 3: adjusted for the same as model 2 with the addition of FN BMD

factors and BMD of the femoral neck. Fracture risk increased as OLST decreased and increased progressively with shorter OLST. Thus, the shorter the time the test subject could stand on one leg, the higher the risk of fracture. Having a low OLST $(<10 \mathrm{~s})$ had a substantial impact of the 10-year probability of major osteoporotic fracture and hip fracture, indicating that the use of OLST could be valuable in assessing the risk of fracture in older women.

In previous studies, low OLST has been shown to be associated both to hip fracture and risk of death [30, 41]. In the present study, we confirm that an OLST $<10$ is associated with increased risk of hip fracture and can also demonstrate that a low OLST is associated with increased risk of major osteoporotic fracture and nonvertebral fracture. OLST was able to predict risk of all these fracture outcomes independently of age, height, weight, FRAX clinical risk factors, and femoral neck BMD. More importantly, a low OLST $(<10 \mathrm{~s})$ increased the 10-year probability substantially in women of all ages and with low to normal BMD, in many instances to risk levels above the $20 \%$, a commonly used treatment threshold [42]. Thus, performing the OLST and considering OLST would have a substantial impact on treatment decisions in women in this age group.

Hip fractures in the elderly have the most far-reaching consequences in terms of disability, reduced quality of life, and increased mortality [43-46]. In addition to individual 

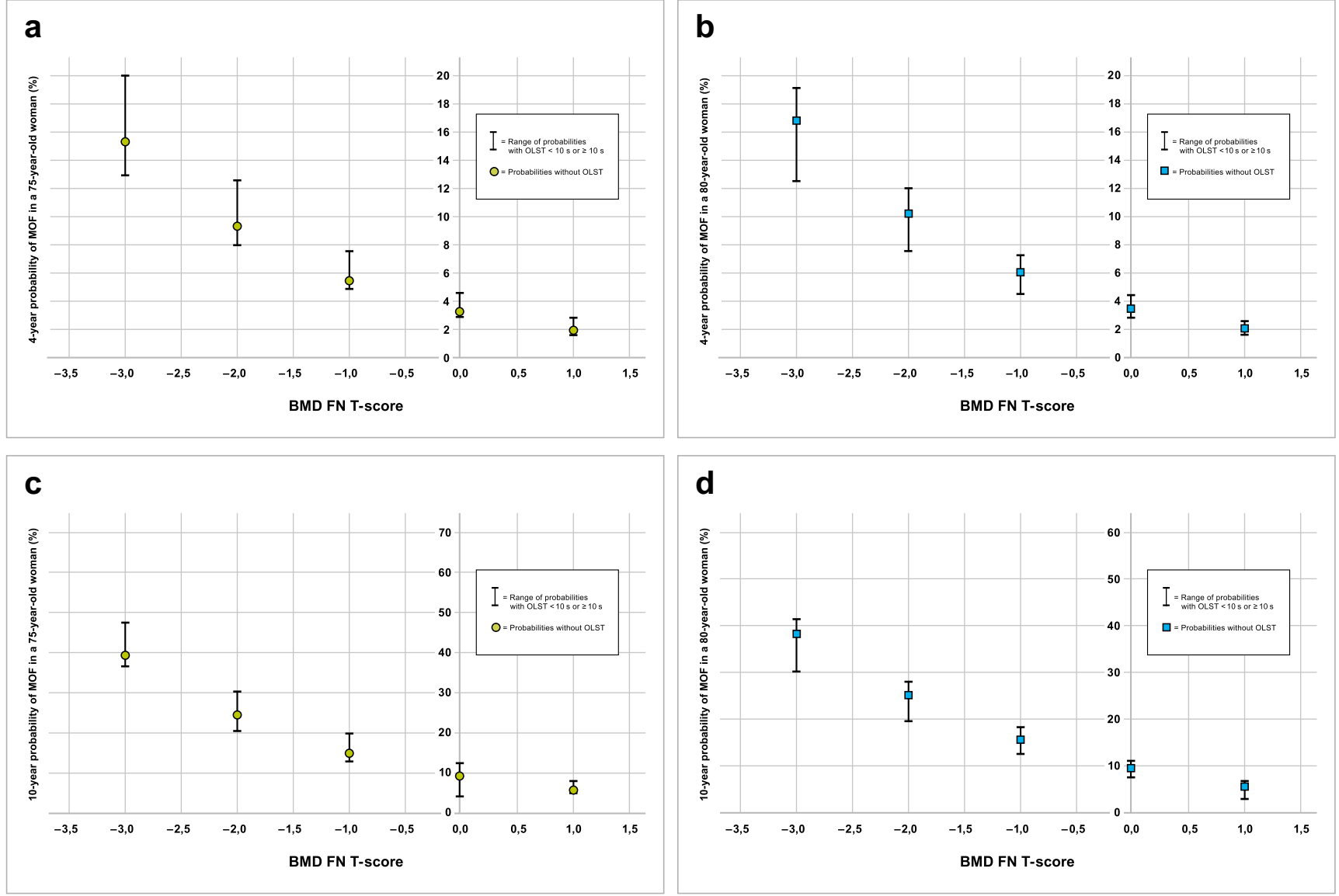

Fig. 2 a, b 4-year probability of major osteoporotic fracture according to femoral neck BMD and OLST. a 4-year probability of a major osteoporotic fracture $(\mathrm{MOF})$ in a 75-year-old woman according to T-score of femoral neck BMD. The symbol (closed circle) denotes probabilities calculated without OLST and the lines denote the range of probabilities with OLST $<10 \mathrm{~s}$ or $\geq 10 \mathrm{~s}$ using the model incorporating OLST. In the used model, BMI is set to $26 \mathrm{~kg} / \mathrm{m}^{2}$, and all clinical risk factors set to no. $\mathbf{b}$ 4-year probability of a major osteoporotic fracture (MOF) in an 80-yearold woman according to T-score of femoral neck BMD. The symbol (closed circle) denotes probabilities calculated without OLST and the lines denote the range of probabilities with OLST $<10 \mathrm{~s}$ or $\geq 10 \mathrm{~s}$ using the model incorporating OLST. In the used model, BMI is set to $26 \mathrm{~kg} /$ $\mathrm{m}^{2}$, all clinical risk factors set to no. c, d 10-year probability of major

osteoporotic fracture according to femoral neck BMD and OLST. c 10year probability of a major osteoporotic fracture (MOF) in a 75-year-old woman according to T-score of femoral neck BMD. The symbol (closed circle) denotes probabilities calculated without OLST and the lines denote the range of probabilities with OLST $<10 \mathrm{~s}$ or $\geq 10 \mathrm{~s}$ using the model incorporating OLST. In the used model, BMI is set to $26 \mathrm{~kg} / \mathrm{m}^{2}$, and all clinical risk factors set to no. $\mathbf{d} 10$-year probability of a major osteoporotic fracture (MOF) in an 80-year-old woman according to T-score of femoral neck BMD. The symbol (closed circle) denotes probabilities calculated without OLST and the lines denote the range of probabilities with OLST $<10 \mathrm{~s}$ or $\geq 10 \mathrm{~s}$ using the model incorporating OLST. In the used model, BMI is set to $26 \mathrm{~kg} / \mathrm{m}^{2}$, and all clinical risk factors set to no

suffering, all fractures in the elderly, but especially hip fractures, are associated with substantial societal costs [47]. A hip fracture can also result in loss of autonomy and that the affected patient could be forced to move to a residential care facility, which for many is a major and very negative and pervasive intervention [12, 48-50]. Thus, new tools, such as the OLST, which could improve the prediction of hip fractures so that they can be more effectively prevented, are urgently needed.

It has been suggested that the OLST could be used as a tool for predicting frailty in community-dwelling older people [31], but the evidence is not entirely consistent [33, 51, 52]. Unlike other physical function tests, such as for example the Timed Up and Go (TUG) test [53-56], it has not previously been definitely established that women with low OLST have generally poorer health than those with normal OLST. However, this hypothesis is clearly supported by the findings in the present study, in which we observe an increased risk of death and a higher prevalence of diseases and frailtyassociated conditions in women with shorter OLST.

An $82 \%$ increased risk of death during follow-up was observed in those with OLST below $10 \mathrm{~s}$ compared to those with a higher OLST. Differences in mortality can affect the associations between OLST and fracture outcomes, since women with low OLST may die before fracturing [57]. Therefore, analyses in the present study were also performed according to Fine and Gray, to adjust for competing risk of mortality. 


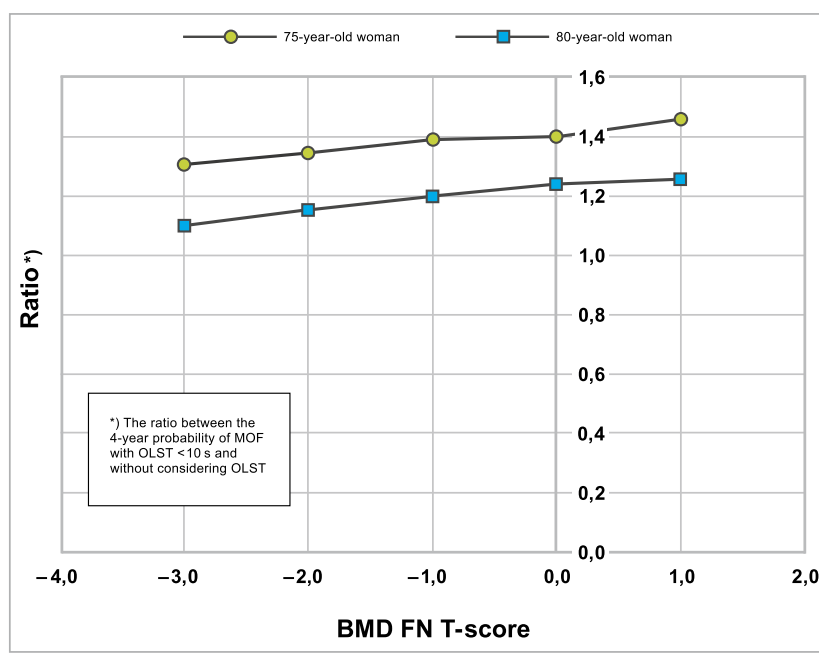

Fig. 3 The ratio between the 4-year probability of major osteoporotic fracture with and without considering OLST is dependent on femoral neck BMD. The ratio between the 4-year probability of major osteoporotic fracture with OLST $<10 \mathrm{~s}$ and without considering OLST, shown for women 75 and 80 years old according to femoral neck BMD T-score. In the used model, BMI is set to $26 \mathrm{~kg} / \mathrm{m}^{2}$, and all clinical risk factors set to no

The clear associations between OLST and fracture risk remained, indicating that the OLST tool is useful also in populations as old as the one herein investigated.

Although it is clear that a short OLST is associated with a high risk of fracture, it is uncertain whether multifactorial interventions, such as balance training and shortening OLST, will decrease the risk of fracture. Several previous studies have shown that multifactorial interventions reduce the risk of falls [58] but the effects on injurious falls, such as fractures, are more unclear [59]. Therefore, we can only speculate as to whether interventions shortening OLST will reduce the risk of fractures.

The current study has some limitations. Only ambulatory women 75-80 years old and able to understand Swedish were included, indicating that the results may not be readily applied to other age groups, women in nursing homes, and women with different ethnic backgrounds.

The OLST was performed by 2405 women while 623 declined to take the test. Women who did not take the test had more comorbidity, higher prevalence of falls and fractures, and a higher baseline FRAX (including BMD) probability, than included women. Thus, the included women are most likely not representative of the female population at this age. Furthermore, when comparing the risk of fracture associated with short OLST observed in this study with results from other studies, it should be noted that there could be procedural differences between studies in how the OLST results were obtained [60], e.g., using different number of attempts, using the average of both legs, or a single maximum value.

Strengths of the study include the large and populationbased sample size with over 2400 women followed prospectively. Furthermore, all identified fractures were identified via X-rays or radiology reports, which enables identification of fractures with high accuracy. In addition, the impact of OLST analyzed together with all currently used FRAX clinical risk factors and BMD in a large population-based study has not previously been investigated and presented before. Nevertheless, future additional studies as well as metaanalyses will be needed to determine if OLST can be an effective addition to the FRAX algorithm.

In conclusion, this study demonstrates that a low OLST is a strong predictor of hip fractures, major osteoporotic fractures, and nonvertebral fractures in older women and that a low OLST substantially increases fracture probability in models including FRAX clinical risk factors and BMD. OLST should be considered as an assessment tool to improve fracture prediction in older women.

Supplementary Information The online version contains supplementary material available at https://doi.org/10.1007/s00198-021-06039-6.

Acknowledgements We would like to thank the late Associate Professor and MD Anna Nilsson for her dedicated work, for being an inspiration, and for her invaluable contributions to the planning of this study, collection of data, and in the interpretations of results. We also express our sincere gratitude to all the study participants in the SUPERB cohort.

Funding Open access funding provided by University of Gothenburg.

\section{Declarations}

Conflicts of interest Professor Lorentzon has received lecture fees from Amgen, Astellas, Lilly, Meda, Renapharma, and UCB Pharma and consulting fees from Amgen, Radius Health, UCB Pharma, Renapharma, and Consilient Health. N. Harvey has received consultancy, lecture fees, and honoraria from Alliance for Better Bone Health, AMGEN, MSD, Eli Lilly, Servier, Shire, UCB, Kyowa Kirin, Consilient Healthcare, Radius Health, and Internis Pharma outside the scope of the submitted work. K. Axelsson has received lecture fees from Lilly, Meda/Mylan, and Amgen. $\mathrm{E}$ McCloskey has received consultancy, research funding, lecture fees, and/or honoraria from AgNovos, Amgen, AstraZeneca, Consilient Healthcare, Fresenius Kabi, GSK, Hologic, Internis, Lilly, ObsEva, Synexus, and UCB outside the scope of this work. All other authors have no conflicts of interest.

Open Access This article is licensed under a Creative Commons Attribution-NonCommercial 4.0 International License, which permits any non-commercial use, sharing, adaptation, distribution and reproduction in any medium or format, as long as you give appropriate credit to the original author(s) and the source, provide a link to the Creative Commons licence, and indicate if changes were made. The images or other third party material in this article are included in the article's Creative Commons licence, unless indicated otherwise in a credit line to the material. If material is not included in the article's Creative Commons licence and your intended use is not permitted by statutory regulation or exceeds the permitted use, you will need to obtain permission directly from the copyright holder. To view a copy of this licence, visit http:// creativecommons.org/licenses/by-nc/4.0/. 


\section{References}

1. Campbell AJ, Borrie MJ, Spears GF (1989) Risk factors for falls in a community-based prospective study of people 70 years and older. J Gerontol 44:M112-M117

2. Khazzani H, Allali F, Bennani L et al (2009) The relationship between physical performance measures, bone mineral density, falls, and the risk of peripheral fracture: a cross-sectional analysis. BMC Public Health 9

3. LaMonte MJ, Wactawski-Wende J, Larson JC et al (2019) Association of physical activity and fracture risk among postmenopausal women. JAMA Netw Open 2

4. Covinsky KE, Palmer RM, Fortinsky RH et al (2003) Loss of independence in activities of daily living in older adults hospitalized with medical illnesses: increased vulnerability with age. J Am Geriatr Soc 51:451-458

5. von Friesendorff M, McGuigan FE, Wizert A et al (2016) Hip fracture, mortality risk, and cause of death over two decades. Osteoporos Int 27:2945-2953

6. Adib Hajbaghery M, Abbasinia M (2013) Quality of life of the elderly after hip fracture surgery: a case-control study. J Caring Sci 2:53-59

7. Gesar B, Hommel A, Hedin H, Baath C (2017) Older patients' perception of their own capacity to regain pre-fracture function after hip fracture surgery - an explorative qualitative study. Int J Orthop Trauma Nurs 24:50-58

8. Alegre-Lopez J, Cordero-Guevara J, Alonso-Valdivielso JL, Fernandez-Melon J (2005) Factors associated with mortality and functional disability after hip fracture: an inception cohort study. Osteoporos Int 16:729-736

9. Center JR, Nguyen TV, Schneider D, Sambrook PN, Eisman JA (1999) Mortality after all major types of osteoporotic fracture in men and women: an observational study. Lancet. 353:878-882

10. Liu Y, Wang Z, Xiao W (2018) Risk factors for mortality in elderly patients with hip fractures: a meta-analysis of 18 studies. Aging Clin Exp Res 30:323-330

11. Johansen A, Mansor M, Beck S, Mahoney H, Thomas S (2012) Outcome following hip fracture: long term mortality and postdischarge residence. Osteoporos Int 23:S545-S545

12. Salkeld G, Cameron ID, Cumming RG et al (2000) Quality of life related to fear of falling and hip fracture in older women: a time trade off study. Brit Med J 320:341-345

13. Cumming RG, Klineberg R, Katelaris A (1996) Cohort study of risk of institutionalisation after hip fracture. Aust N Z J Public Health 20:579-582

14. Veronese N, Maggi S (2018) Epidemiology and social costs of hip fracture. Injury. 49:1458-1460

15. Haentjens P, Lamraski G, Boonen S (2005) Costs and consequences of hip fracture occurrence in old age: an economic perspective. Disabil Rehabil 27:1129-1141

16. Haentjens P, Autier P, Barette M, Boonen S (2001) Belgian Hip Fracture Study G. The economic cost of hip fractures among elderly women. A one-year, prospective, observational cohort study with matched-pair analysis. Belgian Hip Fracture Study Group. J Bone Joint Surg Am 83:493-500

17. Sambrook P, Cooper C (2006) Osteoporosis. Lancet. 367:2010 2018

18. Syed FA, Ng AC (2010) The pathophysiology of the aging skeleton. Curr Osteoporos Rep 8:235-240

19. Hayes WC, Myers ER, Robinovitch SN, Van Den Kroonenberg A, Courtney AC, McMahon TA (1996) Etiology and prevention of age-related hip fractures. Bone. $18: 77 \mathrm{~S}-86 \mathrm{~S}$

20. Lorentzon M, Cummings SR (2015) Osteoporosis: the evolution of a diagnosis. J Intern Med 277:650-661
21. Nilsson M, Eriksson J, Larsson B, Oden A, Johansson H, Lorentzon M (2016) Fall risk assessment predicts fall-related injury, hip fracture, and head injury in older adults. J Am Geriatr Soc 64:22422250

22. Marshall D, Johnell O, Wedel H (1996) Meta-analysis of how well measures of bone mineral density predict occurrence of osteoporotic fractures. BMJ. 312:1254-1259

23. Kanis JA, Harvey NC, Johansson H, Oden A, Leslie WD, McCloskey EV (2017) FRAX update. J Clin Densitom 20:360 367

24. Chang CJ, Chang YS, Yang SW (2013) Using single leg standing time to predict the fall risk in elderly. Conf Proc IEEE Eng Med Biol Soc 2013:7456-7458

25. Vellas BJ, Wayne SJ, Romero L, Baumgartner RN, Rubenstein LZ, Garry PJ (1997) One-leg balance is an important predictor of injurious falls in older persons. J Am Geriatr Soc 45:735-738

26. Hawk C, Hyland JK, Rupert R, Colonvega M, Hall S (2006) Assessment of balance and risk for falls in a sample of community-dwelling adults aged 65 and older. Chiropr Osteopat $14: 3$

27. Drusini AG, Eleazer GP, Caiazzo M et al (2002) One-leg standing balance and functional status in an elderly community-dwelling population in northeast Italy. Aging Clin Exp Res 14:42-46

28. Suni JH, Oja P, Laukkanen RT et al (1996) Health-related fitness test battery for adults: aspects of reliability. Arch Phys Med Rehabil 77:399-405

29. Karkkainen M, Rikkonen T, Kroger H et al (2008) Association between functional capacity tests and fractures: an eight-year prospective population-based cohort study. Osteoporos Int 19:12031210

30. Lundin H, Saaf M, Strender LE, Nyren S, Johansson SE, Salminen $\mathrm{H}$ (2014) One-leg standing time and hip-fracture prediction. Osteoporos Int 25:1305-1311

31. Michikawa T, Nishiwaki Y, Takebayashi T, Toyama Y (2009) One-leg standing test for elderly populations. J Orthop Sci 14: 675-685

32. Lorentzon M, Nilsson AG, Johansson H, Kanis JA, Mellstrom D, Sundh D (2019) Extensive undertreatment of osteoporosis in older Swedish women. Osteoporos Int 30:1297-1305

33. Giorgetti MM, Harris BA, Jette A (1998) Reliability of clinical balance outcome measures in the elderly. Physiother Res Int 3: 274-283

34. Ware J Jr, Kosinski M, Keller SD (1996) A 12-Item Short-Form Health Survey: construction of scales and preliminary tests of reliability and validity. Med Care 34:220-233

35. Washburn RA, McAuley E, Katula J, Mihalko SL, Boileau RA (1999) The Physical Activity Scale for the Elderly (PASE): evidence for validity. J Clin Epidemiol 52:643-651

36. Breslow NE, Day NE (1987) Statistical methods in cancer research. Volume II-The design and analysis of cohort studies. IARC Sci Publ:1-406

37. Albertsson-Wikland K, Martensson A, Savendahl L et al (2016) Mortality is not increased in recombinant human growth hormone-treated patients when adjusting for birth characteristics. J Clin Endocrinol Metab 101:2149-2159

38. Seichi A, Hoshino Y, Doi T et al (2014) Determination of the optimal cutoff time to use when screening elderly people for locomotive syndrome using the one-leg standing test (with eyes open). $\mathrm{J}$ Orthop Sci 19:620-626

39. Nofuji Y, Shinkai S, Taniguchi Y et al (2016) Associations of walking speed, grip strength, and standing balance with total and cause-specific mortality in a general population of Japanese elders. J Am Med Dir Assoc 17:184 e181-184 e187

40. Fine JP, Gray RJ (1999) A proportional hazards model for the subdistribution of a competing risk. J Am Stat Assoc 94:496-509 
41. Rikkonen T, Poole K, Sirola J, Sund R, Honkanen R, Kroger H (2014) Simple functional tests predict hip fracture and mortality in postmenopausal women: a 15-year follow-up. J Bone Miner Res 29:S123-S123

42. Kanis JA, Harvey NC, Cooper C et al (2016) A systematic review of intervention thresholds based on FRAX: a report prepared for the National Osteoporosis Guideline Group and the International Osteoporosis Foundation. Arch Osteoporos 11:25

43. Abrahamsen B, van Staa T, Ariely R, Olson M, Cooper C (2009) Excess mortality following hip fracture: a systematic epidemiological review. Osteoporos Int 20:1633-1650

44. Giversen IM (2007) Time trends of mortality after first hip fractures. Osteoporos Int 18:721-732

45. Cooper C, Campion G, Melton LJ 3rd. (1992) Hip fractures in the elderly: a world-wide projection. Osteoporos Int 2:285-289

46. Colon-Emeric CS, Saag KG (2006) Osteoporotic fractures in older adults. Best Pract Res Clin Rheumatol 20:695-706

47. Abimanyi-Ochom J, Watts JJ, Borgstrom F et al (2015) Changes in quality of life associated with fragility fractures: Australian Arm of the International Cost and Utility Related to Osteoporotic Fractures Study (AusICUROS). Osteoporos Int 26:1781-1790

48. Cunningham TD, Martin BC, DeShields SC, Romero CC (2016) The impact of osteoporotic fractures compared with other health conditions in older adults living in Virginia. United States Osteoporos Int 27:2979-2988

49. van Dijk PA, Bot AG, Neuhaus V, Menendez ME, Vrahas MS, Ring D (2015) Admission from nursing home residence increases acute mortality after hip fractures. Geriatr Orthop Surg Rehabil 6: $123-129$

50. Zimmerman S, Chandler JM, Hawkes W et al (2002) Effect of fracture on the health care use of nursing home residents. Arch Intern Med 162:1502-1508

51. Crosbie WJ, Nimmo MA, Banks MA, Brownlee MG, Meldrum F (1989) Standing balance responses in two populations of elderly women: a pilot study. Arch Phys Med Rehabil 70:751-754
52. Vellas BJ, Rubenstein LZ, Ousset PJ et al (1997) One-leg standing balance and functional status in a population of 512 communityliving elderly persons. Aging (Milano) 9:95-98

53. Viccaro LJ, Perera S, Studenski SA (2011) Is Timed Up and Go better than gait speed in predicting health, function, and falls in older adults? J Am Geriatr Soc 59:887-892

54. Lin MR, Hwang HF, Hu MH, Wu HD, Wang YW, Huang FC (2004) Psychometric comparisons of the Timed Up and Go, oneleg stand, functional reach, and Tinetti balance measures in community-dwelling older people. J Am Geriatr Soc 52:13431348

55. Beauchet O, Fantino B, Allali G, Muir SW, Montero-Odasso M, Annweiler C (2011) Timed Up and Go test and risk of falls in older adults: a systematic review. J Nutr Health Aging 15:933-938

56. Melzer I, Kurz I, Sarid O, Jette AM (2007) Relationship between self-reported function and disability and balance performance measures in the elderly. J Rehabil Res Dev 44:685-691

57. Berry SD, Ngo L, Samelson EJ, Kiel DP (2010) Competing risk of death: an important consideration in studies of older adults. J Am Geriatr Soc 58:783-787

58. Gillespie LD, Robertson MC, Gillespie WJ et al (2012) Interventions for preventing falls in older people living in the community. Cochrane Database. Syst Rev 2012:Cd007146

59. Lamb SE, Bruce J, Hossain A et al (2020) Screening and intervention to prevent falls and fractures in older people. N Engl J Med 383:1848-1859

60. Bohannon R (2006) Single limb stance times: a descriptive metaanalysis of data from individuals at least 60 years of age. Topics in Geriatric Rehabilitation 22:70-77

Publisher's note Springer Nature remains neutral with regard to jurisdictional claims in published maps and institutional affiliations. 